\title{
Use of repopulation for optimizing sow reproductive performance and piglet loss
}

\author{
Pavel Nevrkla, Marie Čechová, Zdeněk Hadaš \\ Mendel University in Brno, Faculty of Agronomy, Department of Animal Breeding, Czech Republic \\ Received March 18, 2014 \\ Accepted July 23, 2014
}

\begin{abstract}
The objective of this study was to analyse sow reproductive performance and piglet loss from birth to weaning before and after repopulation of a selected farm. The observation was carried out on a productive sow farm; 160 sows were included in the experiment. Before repopulation, 80 sows from the $1^{\text {st }}$ to the $5^{\text {th }}$ litter were evaluated. The original population of sows was removed. Repopulated (newly stocked) group consisted of 80 gilts at the $1^{\text {st }}$ litter. Newly delivered gilts with a status of minimum disease were placed into a decontaminated stable with a strict batch, black and white breeding system with stringent hygienic provisions. The piglets were weaned at the mean age of $28 \pm 3$ days. A very highly significant difference $(P \leq 0.001)$ in favour of the repopulated group of sows was found in the evaluation of the total number of piglets, the number of live-born piglets and the number of stillborn piglets in \%; a significant difference $(P \leq 0.05)$ in favour of the repopulated group of sows was found in the number of stillborn piglets. In reared piglets and losses of piglets, both in numbers and percentage, a highly significant difference $(P \leq 0.001)$ was found in favour of the repopulated group. This study brings important information on the benefits of repopulation pig breeding.
\end{abstract}

Diseases, health of pigs, rearing, reproduction traits, status with minimum disease

An essential condition for effective breeding of sows is to ensure good health and high performance of sows, which determine the number of reared piglets per sow (Boudný and Śpička 2012; Horký et al. 2013). Rodríguez et al. (2012) consider the number of reared piglets a major economic effect of breeding sows. Optimal reproductive management is beside various endogenous and exogenous factors influenced by the health condition, which is then reflected in rearing and fattening of pigs and therefore in whole profitability of a farm. Poor health situation in herds negatively influences the farm economy (Lambert et al. 2012).

According to Opriessnig et al. (2011) great economic losses are caused worldwide by infectious or bacterial diseases of the respiratory tract of piglets. Smola and Masaříková (2007) report that these diseases occur in various combinations, causing the porcine respiratory disease complex (PRDC).

Bad health situation on farms can be solved by the system of radical repopulation method (Guedes et al. 2002). According to O'Donoghue and Ballantyne (1965) the principle of the repopulation method lies in the disruption or restriction of the contact of born piglets with their mothers and isolated rearing of the young. The major advantage of this method is the possibility of herd recovery from all diseases which are not transmissible in utero while maintaining the genetic potential. The method consists of extracting piglets shortly before birth either by Caesarean section or by extraction of the whole uterus (hysterectomy) or by aseptic capture of piglets (Young 1960). According to Nevrkla et al. (2013), the disease's life cycle can be interrupted this way as there is no contact between piglets and sow. This method is known as status with minimum disease (MD). The method is economically more demanding than conventional rearing of piglets by sows. Therefore, it is recommended 
for production of pigs on breeding or reproductive farms. On production farms sows give birth naturally (Jorsal and Thomsen 1988). It is necessary to follow the rules of biosecurity to prevent reinfection in a repopulated farm (Laanen et al. 2013). Jorsal and Thomsen (1988) state that the method or repopulation and creating MD herds should have a positive effect on reproductive performance of sows, piglet loss reduction, improvement of productive properties of pigs, improvement of the herd health situation and therefore reduction of treatment costs.

The objective of the work was an analysis of sow reproductive performance and piglet loss from birth to weaning after repopulation of a selected farm.

\section{Materials and Methods}

The observation was carried out on a productive sow farm, where 160 sows were included in the experiment. The experiment was approved by the Ethics Committee of Mendel University Brno (accreditation no. 57890/2012MZE-17214).

Before repopulation, 80 sows from the $1^{\text {st }}$ to the $5^{\text {th }}$ litter were evaluated.

In the group of sows before repopulation, virological and serological tests (Table 1) were performed in the diagnostic laboratory of the State Veterinary Institute in Olomouc and Jihlava for the presence of porcine respiratory and reproductive syndrome (PRRS), porcine circovirus (PCV-2), porcine parvovirus (PPV), Aujezsky's disease (AD), brucellosis (BA) and classical swine fever (CSF). ELISA test was used for the diagnostics of PRRS, PCV2, AD and CSF. Haemagglutination-inhibition test was used for the presence of PPV. BA was diagnosed by the complement fixation (CF) and Rose Bengal test (RBT).

Table 1. Diagnostics of the presence of disease in blood samples.

\begin{tabular}{lccc}
\hline Disease & Samples tested & Positive samples & Negative samples \\
\hline PRRS (E.s.) & 5 & 5 & 0 \\
PCV-2 & 5 & 3 & 2 \\
PPV & 5 & 5 & 0 \\
AD & 2 & 0 & 2 \\
BA & 2 & 0 & 2 \\
CSF & 2 & 0 & 2 \\
\hline
\end{tabular}

PRRS - porcine respiratory and reproductive syndrome, E.s. - European strain, PCV-2 - porcine circovirus, PPV - porcine parvovirus, AD - Aujezsky's disease, BA - brucellosis, CSF - classical swine fever , ${ }^{*}$ Data relating to IgG antibodies confirming PCV-2 infection in the past. IgM antibodies indicative of acute infection were not detected in any sample.

The original population of sows was removed. Repopulated (newly stocked) group consisted of 80 gilts at the $1^{\text {st }}$ litter. Animals of both groups were of the same hybrid combination.

Newly delivered MD gilts were placed into a decontaminated stable with a strict batch, black and white breeding system with stringent hygienic provisions. Stable entry was via one main entrance with mandatory showering, clothing and footwear exchange for all nursing staff and visitors. Each building entrance was equipped with a disinfection mat for disinfection and cleaning of footwear. A strict control of the movement of persons and visitors in the area of the farm was applied and the entrance of those who came into contact with other pigs during the last 3 days or who breed pigs at home was prohibited. Gilts were brought from approved source farm applying the same strict measures as the observed farm. The group of newly brought breeding gilts were first acclimated and then stabled in quarantine. Vehicles were properly cleaned and disinfected before entering the farm, drivers were not allowed to move either in the area of the farm or in the stables. Vectors such as insect and rodents which are considered viral infection carriers had to be regularly eliminated by means of disinfection and deratization.

Movement of piglets among litters was disabled, except for the first $24 \mathrm{~h}$ after birth when necessary. Injection needles and other supplies were used only for one litter. Windows of stables for both served and pregnant sows were equipped with nets against birds and insect. Thorough cleansing and disinfection of stables was performed after batch emptying of each section.

The piglets were weaned at the mean age of $28 \pm 3$ days. In both groups of sows (before and after repopulation) the phenotypic level of selected reproductive properties was observed: namely, the total number of born piglets, 
the number of live-born piglets, the number of stillborn piglets, the number of reared piglets, and piglet losses from birth to weaning.

The obtained reproductive indicators and piglet losses before repopulation were compared to the indicators obtained after repopulation, and elementary statistical characteristics for differences in the evaluated indicators between the groups of gilts were analysed; namely, mean, standard deviation (mean \pm S.D.), and significance based on $t$-test. The symbol *** stands for $P \leq 0.001$, ** stands for $P \leq 0.01$, * stands for $P \leq 0.05$ and NS stands for $P \geq$ 0.05. The statistical evaluation was done using the STATISTICA version 10.0 software and Microsoft Excel 2010.

\section{Results}

The repopulation of sows led to an increase of reproductive performance. Table 2 presents the phenotypic level of sow performance in the total number of piglets, the number of liveborn and stillborn piglets per litter before and after repopulation of the farm. A highly significant difference $(P \leq 0.001)$ in favour of the repopulated group of sows was found in the total number of piglets, the number of live-born piglets, and the number of stillborn piglets in $\%$; a significant difference $(P \leq 0.05)$ in favour of the repopulated group of sows was found in the number of stillborn piglets. Application of farm repopulation brought an increase of the total number of piglets by 2.72 per litter in repopulated sows. The number of live-born piglets increased by 3.25 piglets per litter and the number of stillborn piglets decreased by 0.54 (5.36\% difference).

Table 2. Basic statistical characteristics of the total number of piglets, the number of live-born and stillborn piglets.

\begin{tabular}{lrccc}
\hline Indicator & Criterion & N. of piglets & Mean \pm S.D. & Significance \\
\hline Total number of piglets / litter & I & 1057 & $13.21 \pm 2.51$ & $* * *$ \\
& II & 1274 & $15.93 \pm 2.20$ & $*$ \\
Number of live-born piglets / litter & I & 910 & $11.38 \pm 2.20$ & $* * *$ \\
& II & 1170 & $14.63 \pm 2.09$ & $*$ \\
Number of stillborn piglets / litter & I & 147 & $1.84 \pm 1.57$ & $*$ \\
Number of stillborn piglets (\% / litter) & II & 104 & $1.30 \pm 1.36$ & $* * *$ \\
& I & 147 & $13.20 \pm 10.44$ & \\
\hline
\end{tabular}

*** $P \leq 0.001 ; * P \leq 0.05 ; \mathrm{I}$ - before repopulation; II - after repopulation

Table 3. Basic statistical characteristics of the number of reared piglets and losses of piglets from birth to weaning.

\begin{tabular}{lrccc}
\hline Indicator & Criterion & N. of piglets & Mean \pm S.D. & Significance \\
\hline \multirow{2}{*}{ Number of live-born piglets / litter } & I & 910 & $11.38 \pm 2.20$ & $* * *$ \\
& II & 1170 & $14.63 \pm 2.09$ & \\
Number of reared piglets / litter & I & 752 & $9.40 \pm 1.80$ & $* * *$ \\
& II & 1075 & $13.44 \pm 1.78$ & $* * *$ \\
Loss of piglets / litter & I & 161 & $2.01 \pm 1.45$ & $* * *$ \\
& II & 95 & $1.19 \pm 1.47$ & $*$ \\
Loss of piglets (\% / litter) & I & 161 & $16.10 \pm 10.68$ & $* * *$ \\
& II & 95 & $7.51 \pm 9.02$ & \\
\hline
\end{tabular}

*** $P \leq 0.001$; I - before repopulation; II - after repopulation

Table 3 shows the numbers of reared piglets and piglet losses from birth to weaning per one litter. Between both weaned piglets and their losses, in numbers and in percentage, a highly significant difference $(P \leq 0.001)$ was proved in favour of the repopulated group. 
The repopulation of sows increased the number of reared piglets from one sow per litter by 4.04 piglets. An important criterion for evaluation of the application of farm repopulation is piglet loss. The difference between the groups was 0.82 piglets in favour of the repopulated sows. In percentage, the difference between the groups of piglets was $8.59 \%$.

\section{Discussion}

Damgaard et al. (2003) point out that litter size affects the survival of piglets after birth. Olanratmanee et al. (2010) report 12.1 born piglets per litter for sows in good hygienic conditions vs. 11.7 born piglets for sows in poor hygienic conditions which indicates the need for a good health status of breeding sows; they further found 10.3 liveborn piglets per litter for sows with health problems compared to 11.1 live-born piglets for sows without health problems. Lewis et al. (2009) state that PRRS virus influences reproductive performance of sows and gilts. Their results show that healthy gilts at the first litter had over 9 live-born piglets compared to only 7 live-born piglets of gilts with health issues; furthermore they found 3.0 stillborn piglets per litter for diseased gilts and 0.6 stillborn piglets per litter for healthy sows. Their observation highlighted higher incidence of stillborn piglets in gilts. According to Cozler et al. (1998) the number of reared piglets is used for expressing sow performance. These authors note that sow productivity depends mainly on the genetics and farm management, which includes also appropriate health programs. Lewis et al. (2009) found 7.5 reared piglets per litter for sows with health problems compared to 9.25 reared piglets per litter for healthy sows.

O'Donoghue and Ballantyne (1965) report that specific pathogen free (SPF) sows are characterized by lower losses of piglets before weaning, but they emphasize that repopulation itself is not sufficient and that it is necessary to ensure strict hygiene in the herd. Munsterhjelm et al. (2006), Andersen et al. (2009), and Oliviero et al. (2010) state that appropriate health programs in sow herds minimize piglet loss after birth. According to Rootwelt et al. (2012) the loss of piglets from the live-born to the weaned in problematic herds reaches up to $16.20 \%$. Jung et al. (2008) state that viral infections present in some herds can increase mortality of newborn piglets, adding that rotavirus infections are the cause of acute diarrhoea in suckling piglets and outbreaks of these infections are associated with an impaired immune system response. Vaillancourt et al. (1992) report that intensive sow production is accompanied by certain critical phases. Loss of piglets from birth to weaning is considered an important one, either as a result of infectious diseases or nonpathogenic causes; therefore, monitoring of piglets allows its optimization. They also point out that in problematic herds the losses can be very high. For example, piglet loss before weaning in the worst herds reached $12-30 \%$ in England, 17.6\% in Croatia, and $22.2 \%$ in Slovenia.

Values of the observed reproductive indicators and piglet loss can be considered very competitive from the current perspective after repopulation, therefore the recovery of farms by means of repopulation and creating MD farms can be recommended. Strict rules of biosecurity are a necessity on repopulated farms for maintaining a good health status of sows and piglets, which can have an impact on better sow performance of sows and piglet survival.

\section{Acknowledgement}

This study was supported by the project of MENDELU Internal Grant Agency, Faculty of Agriculture No. TP 5/2014, and the NAZV Project No. QI 111A166 of the Ministry of Agriculture of the Czech Republic.

\section{References}

Andersen IL, Haukvik IA, Boe KE 2009: Drying and warming immediately after birth may reduce piglet mortality in loose-housed sows. Animal 4: 592-597 
Boudný J, Špička J 2012: The effect of production efficiency on economic results in pig breeding. Res Pig Breed 6: $1-8$

Cozler YL, Dagorn J, Lindberg JE, Aumaitre A, Dourmad JY, 1998: Effect of age at first farrowing and herd management on long-term productivity of sows. Livest Prod Sci 53: 135-142

Damgaard LH, Rydhmer L, Løvendahl P, Grandinson K 2003: Genetic parameters for within-litter variation in piglet birth weight and change in within-litter variation during suckling. J Anim Sci 81: 604-610

Guedes RMC, Gabhart CJ, Armbruster GA, Roggow BD 2002: Serologic follow-up of a repopulated swine herd after an outbreak of proliferative hemorrhagic enteropathy. Can J Vet Res 66: 258-263

Horký P, Ruttkay-Nedecky B, Kremplova M, Krystofova O, Kensova R, Hynek D, Babula P, Zitka O, Zeman L, Adam V, Kizek R 2013: Effect of different doses of organically bound selenium on antioxidant status and levels of metal ions in postpartum sows. Int J Electrochem Sc 8: 6162-6179

Jorsal SE, Thomsen BL 1988: A cox regression analysis of risk factors related to Mycoplasma suipneumoniae reinfection in Danisch SPF-herds. Acta Vet Scand 84: 436-438

Jung K, Kong BK, Lee CHS, Song DS 2008: Impact of porcine group A rotavirus co-infection on porcine epidemic diarrhea virus pathogenicity in piglets. Res Vet Sci 84: 502-506

Laanen M, Perssons D, Ribbens S, De Jong E, Callens B, Strubbe M, Maes D, Dewulf J 2013: Relationship between biosecurity and production/antimicrobial treatment characteristics in pig herds. Vet J 198: 508-512

Lambert MČ, Poljak Z, Arsenault J, D'allaire S 2012: Epidemiological investigations in regard to porcine reproductive and respiratory syndrome (PRRS) in Quebec, Canada. Part 1: Biosecurity practices and their geographical distribution in two areas of different swine density. Prev Vet Med 104: 74-83

Lewis CRG, Torremorell M, Bishop SC 2009: Effects of porcine reproductive and respiratory syndrome virus infection on the performance of commercial sows and gilts of different parities and genetic lines. J Swine Health Prod 3: 140-147

Munsterhjelm C, Valros A, Heinonen M, Halli O, Peltoniemi OAT 2006: Welfare index and reproductive performance in the sow. Reprod Domest Anim 41: 494-500

Nevrkla P, Čechová M, Hadaš Z 2013: Evaluation of selected reproductive parametres in gilts and loss of piglets after repopulation. Acta Univ Agric Et Silvic Mendel Brunen 61: 1357-1364

O'Donoghue JG, Ballantyne EE 1965: Observations on a swine herd health program. Can J Comp Med Vet Sci 29: $317-323$

Olanratmanee E, Kunavongkrit A, Tummaruk P 2010: Impact of porcine epidemic diarrhea virus infection at different periods of pregnancy on subsequent reproductive performance in gilts and sows. Anim Reprod Sci 122: $42-51$

Oliviero C, Heinonen M, Valros A, Peltoniemi O 2010: Environmental and sow-related factors affecting the duration of farrowing. Anim Reprod Sci 119: 85-91

Opriessnig T, Gimenez-Lirola LG, Halbur PG 2011: Polymicrobial respiratory disease in pigs. Anim Health Res Rev 12: $133-148$

Rodríguez SV, Plá LM, Albornoz VM 2012: Modeling tactical planning decisions through a linear optimization model in sow farms. Livest Sci 143: 162-171

Rootwelt V, Reksen O, Framstad T 2012: Production traits of litters in 2 crossbred Duroc pig lines. J Anim Sci 90: $152-158$

Smola J, Masaříková M 2007: Enteric infections in piglets - an update on diagnostics, treatment and vaccination strategies to control bacterial agents. Res Pig Breed 1: 68-69

Vaillancourt JP, Marsh WE, Dial GD 1992: Internal consistency of preweaning mortality datacollected by swine production. Prev Vet Med 14: 115-128

Young GA 1960: Farm repopulation with "Disease-Free" pigs. Mod Vet Pract 41: 32 